\title{
LITERATURA JOVEM ADULTO, PROJETO DE EXTENSÃO E A DEMOCRATIZAÇÃO DO CONHECIMENTO: A LEITURA COMO UM DIREITO CIDADÃO
}

\author{
YOUNG ADULT LITERATURE, EXTENSION PROJECT AND THE DEMOCRATIZATION OF \\ KNOWLEDGE: READING AS A CITIZEN RIGHT
}

\author{
Martha Julia Martins de Souza ${ }^{1}$ \\ ${ }^{1}$ Universidade Federal de Roraima (UFRR), Boa Vista, RR, Brasil \\ marthajumartins@gmail.com
}

Recebido em 6 jul. 2019

Aceito em 25 out. 2019

\begin{abstract}
Resumo: $O$ presente trabalho é resultado da experiência da pesquisadora em conduzir um projeto de extensão voltado para a leitura de livros em inglês do gênero YA (young adult/jovem adulto). A iniciativa, que surge no ano de 2018, parte de levantamento de necessidade feito por esta pesquisadora, durante a condução das disciplinas de Literaturas de Língua Inglesa, que verificou que parte considerável dos alunos não conseguia ler os clássicos da língua inglesa ou apresentavam compreensão limitada dos textos trabalhados em sala. Nesse contexto, a proposta de um Clube de Leitura de Young Adult (YA) em uma universidade pública federal, na região Norte do país, apresentase como uma prática social que integra o ensino formal de Língua Inglesa à democratização da leitura em língua estrangeira, em um país de tamanho continental, cujo acesso a livrarias e bibliotecas com acervo significativo apresenta-se insuficiente em muitos lugares do país. Metodologicamente, esse trabalho se estrutura com base em questionários, diário de bordo das leituras, falas e interações dos alunos participantes, e analisa esses dados sob a ótica do pensamento decolonial (MIGNOLO; WALSH, 2018; GROSFOGUEL, 2016). A pesquisa e o projeto de extensão, que caminham para seu segundo ano, vão além da formação de leitores de uma língua estrangeira hegemônica, mas servem ao propósito político e pedagógico de mobilizar uma juventude cidadã que anseie por uma sociedade mais justa, igualitária e consciente dos discursos de preconceito e ódio que se manifestam na sociedade atual.
\end{abstract}

Palavras-chave: Projeto de extensão. Literatura jovem adulto. Língua Inglesa. Decolonialidade.

\begin{abstract}
The present work is the result of this researcher's experience in conducting an extension project aimed at reading books in English of YA (Young Adult) genre. The initiative, which arose in the year 2018, starts from a survey made by this researcher during the English Language Literature Discipline, who noticed that a considerable amount of students could not read English classics or had a very limited understanding of the texts worked in class. In this context, the proposal of a Young Adult (YA) Reading Club at a Federal Public University in the northern region of the country presents itself as a social practice that integrates the formal teaching of English to the democratization of reading in a foreign language, in a country of continental size, whose access to bookstores and libraries with significant collection is insufficient in many regions of the country. Methodologically, this work is structured based on questionnaires, logs, talks, and interactions with the participating students, and analyzes these data, from the point of view of decolonial thinking (MIGNOLO; WALSH, 2018; GROSFOGUEL, 2016). The research and extension project, which are going to their second year, go beyond the training of readers of a foreign hegemonic language, but it serves the political and pedagogical purpose of mobilizing young citizens who yearns for a more just, egalitarian and conscious society of the discourses of prejudice and hatred that are manifested in today's society.
\end{abstract}

Keywords: Extension project. Young adult literature. English. Decoloniality. 


\section{INTRODUÇÃO}

Existe um discurso recorrente no senso comum que reforça a ideia equivocada de que no Brasil os jovens não leem ou de que o brasileiro não gosta de ler. Todos esses estereótipos que rondam a informalidade discursiva partem de um local verticalizado que determina a qualidade e a quantidade de leitura validada através do cômputo de livros comprados, efetivamente, em livrarias no Brasil. Definir o público leitor através da quantidade de livros que são vendidos no Brasil pode gerar uma compreensão equivocada acerca do perfil de leitores do país, uma vez que se desconsidera, nesse ensejo, empréstimo de livros em bibliotecas, downloads gratuitos (pirataria digital), empréstimos entre parentes e amigos, etc.

De acordo com a $4^{a}$ edição da pesquisa Retratos da Leitura no Brasil, realizada em parceria com o IBOPE e o Instituto Pró-Livro em 2016, 56\% da população brasileira é considerada leitora, cujo critério da pesquisa foi: ter lido ao menos 1 livro ou partes de 1 livro, nos 3 meses anteriores à pesquisa. Na pesquisa de 2011, esse número era de $50 \%$. Ainda de acordo com os dados de 2016, dos indivíduos que fizeram Ensino Superior, a maioria declarou que lê, porque gosta ou sente prazer na leitura (INSTITUTO PRÓ-LIVRO, 2016).

Os resultados estão longe de serem ideais, mas ao menos demonstram que o interesse pela leitura aumenta, à medida que a renda do indivíduo amplia, e consequentemente, o acesso que esse indivíduo tem a livros e momentos reservados ao dia para se dedicar ao hábito de ler. Em outras palavras, a promoção do desenvolvimento econômico e justiça social em determinado país - aliado a boas políticas públicas e práticas voltadas para o incentivo à leitura - afetam positivamente a formação de leitores em um país. Para a antropóloga francesa, Michèle Petit, estudiosa dos hábitos de leitura, há cerca de 20 anos, tais discursos alarmistas "por virem dos poderes públicos, dos professores, dos pais ou dos editores, podem ser percebidos como outras tantas ordens, como testemunhos de impaciência, de uma vontade de controle, de domínio" (2013, p. 22), o que poderia desincentivar ou reforçar negativamente a relação do indivíduo com o livro.

A leitura, que era percebida pelas gerações anteriores como manifestação da expressão identitária ou como forma de resistência contra repressão familiar e social, corre o risco de hoje ser percebida como ato de submissão, prática 
obrigatória atrelada a fins educacionais ou profissionais, dissociando-se a leitura do simples prazer (PETIT, 2013). Da obrigação de ler certos gêneros literários e certos autores, perde-se o encontro propiciado pelos livros. Na França, ainda segundo a autora, o gênero jovem adulto vem sendo aos poucos introduzidos na sala de aula. As crianças são convidadas a fazerem fichamentos e a se expressarem diante dos colegas de classe acerca do livro lido (PETIT, 2013).

O gênero jovem adulto (young adult, como é conhecido no mundo anglofônico), é literatura contemporânea voltada para o público jovem - entre 12 e 18 anos. É bastante controverso o alcance englobado pela literatura YA, pois alguns acreditam que o público-alvo começa aos 12 anos e vai até os 21; há, ainda, outros que defendem que o público leitor de YA vai até os 29 anos. Independentemente da idade, esse gênero literário atrai muitos leitores - seja em busca de literatura de diversão, com linguagem mais acessível, seja em busca dos textos originais que dão origem a filmes e séries na atualidade. Nos últimos anos, livros como a Saga Crepúsculo (The Twilight Saga) a Trilogia Jogos Vorazes (The Hunger Games Trilogy) e As vantagens de ser invisivel (The Perks of Being a Wallflower) viraram filmes com roteiro baseado nos livros.

Não é incomum que os livros de YA sejam classificados como subgênero de ficção ou como literatura de massa e, portanto, inferiorizados por leitores e não aceitos na academia.

Para Jaime Ginzburg, reconhecer a qualidade de uma obra está restrito a grupo privilegiado. Isso assegura:

[...] que apenas poucos eleitos sejam reconhecidos como capazes de atribuir valor de modo legítimo, e que não reste alternativa aos leitores leigos a não ser segui-los em obediência, há várias estratégias conhecidas. Uma delas é comum e constante: afirmar que o valor de uma obra é inteiramente inerente a ela". "Valor" então seria uma substância, não uma atribuição; um dado a priori, não uma construção histórica. Bons leitores o reconhecem, leitores fracos nada veem. Essa perspectiva comum não é apenas arrogante intelectualmente, ela é francamente autoritária. $\mathrm{O}$ valor considerado inerente à obra consiste em capital intelectual, indicador de relevância e prestígio de quem o reconhece (GINZBURG, 2008, p. 101).

Ao negar espaço ao YA, nega-se aos leitores o direito de ler obra de linguagem mais acessível em língua estrangeira - especialmente aos que estão aprendendo a ler em um novo idioma - de discutir temáticas atuais, típicas do gênero YA, como representatividade homoafetiva, violência contra negros, desigualdade estrutural, despertar da sexualidade e perdas afetivas. Nega-se ainda, a oportunidade de 
acesso e interesse futuro a obras do cânone ou obras de maior reconhecimento da academia, pois uma vez adquirido o hábito de leitura, os novos leitores enveredam por leituras de maior complexidade, conforme observado no projeto de extensão literário do presente estudo que propiciou o entendimento de que as verdades e as convicções (literárias) reforçam padrões de privilégio e desigualdade desinteressante à nação leitora que se pretende construir. Parece consenso entre os participantes do projeto de extensão literário, a que esse trabalho se refere, que uma obra contemporânea como Harry Potter, da autora inglesa J. K. Rowling, seja mais confortável e acessível a um público não leitor do que a vasta maioria de autores consagrados na literatura brasileira e mundial. Como diz Ginzburg:

Se as verdades humanas são eternas, invariáveis, pouco importam os conflitos históricos circunstanciais, as contingências tensas. Evidentemente não é assim que pensam o feminismo e o movimento negro. A defesa de verdades eternas pode coincidir, convenientemente, com o reforço do recalque da violência histórica (...). Ela serve para reforçar as condições de desigualdade e exclusão e silenciar as vozes de segmentos sociais que historicamente não tiveram direito à manifestação no campo das letras (GINZBURG, 2008, p. 102).

Dentre as vantagens do gênero literário YA estão o impulsionamento do mercado editorial no mundo voltado para um público leitor jovem, o espaço concedido a autoras mulheres que costumam ser maioria mercado de YA, e, no que diz respeito diretamente a esse trabalho, o gênero YA faz da leitura uma prática mais atraente a um público não leitor, consequentemente, empoderando novos indivíduos a fazerem parte do universo da leitura. O motivo principal pelo qual esse tipo de literatura faz relativo sucesso entre o público jovem ou o público com pouco acesso à literatura canônica (quaisquer que sejam os motivos) diz respeito, principalmente às temáticas desenvolvidas nessas obras, que versam sobre problemas e dilemas enfrentados pelos jovens em idade de formação, como os romances coming-of-age ou romances do ápice da maturidade, em tradução livre, sobre doenças como a depressão e outros transtornos de ansiedade, sobre o primeiro amor, sobre a adaptação em uma nova escola, bullying, rejeição, violência, entre outros, tornando esses livros mais interessantes - uma vez que tratam de assuntos facilmente relacionáveis - e apelativos a pessoas de qualquer idade, classe social ou nível de escolaridade.

A literatura YA não é recente no mercado editorial. Grandes clássicos da ficção mundial, escritos em língua inglesa, notabilizaram-se ao longo dos anos e viraram 
foco de estudo nos cursos de graduação de Letras Inglês no mundo todo. Embora não fossem originalmente escritos para o público jovem adulto, muitos desses títulos aclamados como cânones literários, acabaram virando precursores do segmento. É o caso de As aventuras de Tom Sawyer e As Aventuras de Huckleberry Finn do autor norte-americano, Mark Twain, obras do século XIX que conquistaram não apenas o público jovem, como também outras gerações seduzidas pela escrita primorosa e inventividade dos temas discutidos nas duas obras. Na década de 1950, o destaque vai para O Apanhador no Campo de Centeio de J. D. Salinger e O Senhor das Moscas de William Golding. Todavia, foi com a série Harry Potter da autora britânica J. K. Rowling, que o gênero jovem adulto ou YA foi efetivamente consagrado. Aclamada pela maturidade de sua escrita, a série Harry Potter transporta o leitor para uma fábula moderna sobre um herói que precisa vencer obstáculos para mudar o mundo.

Os YAs contemporâneos caracterizam-se pela linguagem simples e acessível; seguem enredo, geralmente linear, com personagens fáceis de se conectar. Como grande parte dessa literatura Jovem Adulto é escrita em língua inglesa, o uso desse material autêntico em sala de aula ou nos encontros do projeto de extensão em questão muito beneficia alunos que estão aprendendo a língua ou até mesmo aqueles que gostariam de aperfeiçoar a importante habilidade de leitura na língua estrangeira. Ao contrário dos livros clássicos, os livros de YA, que possui linguagem com estruturas morfossintáticas relativamente simples e com conteúdos que exploram muitas vertentes de discussão, não apresentam o estigma de serem obras densas, difíceis ou cultas, o que atrai público amplo, geralmente receoso de iniciar a leitura de livros clássicos.

Nesse sentido, um projeto de extensão que tenha por base a leitura de obras de YA torna-se um relevante aliado da prática acadêmica, pois: propicia discussão de temas de interesse comum a muitas pessoas, uma vez que contempla obras mais hodiernas e que situem o aluno em contexto histórico mais próximo de suas próprias realidades; cumpre o papel fulcral de cativar e incentivar a leitura em língua estrangeira, principalmente no caso em questão, onde a própria língua estrangeira é o obstáculo, seja por: (i) questões financeiras - uma vez que livros em inglês costumam ser mais caros do que a média, por serem importados, e consequentemente inacessíveis a muitos alunos do ensino superior; (ii) questões de 
acesso e estudo à língua estrangeira, pois nem todos os alunos tiveram a chance de ensino formal da língua; (iii) por questões emocionais, em que alguns alunos apresentam inibições pessoais e inseguranças de praticar a língua estrangeira, de ler livros em língua estrangeira, principalmente os clássicos, e se expor frente a um grupo maior. E é nesse sentido, então, que se concretiza a relevância social e técnica do projeto de extensão em questão. Ademais, o projeto de extensão favorece a prática de estruturas linguísticas em língua inglesa, aliando prazer e aprendizado.

Para Boaventura de Sousa Santos, os cânones literários, estáveis e facilmente reconhecíveis, no mundo ocidental, passaram a ser questionados a partir do advento de novas teorias ligadas ao feminismo e a problematizações étnicas, culturais e sociais, particularmente nos países de origem anglo-saxã, ao longo de todo o século XX. O capital cultural das obras que fazem parte do cânone literário e bíblico são inegáveis e a segurança com que foram estabelecidos na sociedade deve-se aos anos de práticas institucionais que contribuíram para legitimar sua consolidação. Para esse autor, o dispositivo ideológico que gera a desigualdade e a exclusão no mundo é o universalismo. É através da imposição desse universalismo, que diferenças socioculturais são suprimidas, homogeneizando as práticas culturais e sociais em que os indivíduos estão inseridos (SANTOS, 2010). Embora o objetivo dessa pesquisa não seja questionar a validade e importância dos cânones, 0 presente estudo visa trazer à luz da reflexão acadêmica sob a ótica do pensamento decolonial, outras formas de conceber o aprendizado da língua inglesa, outros saberes, outras formas de escrita e leitura, outros textos, outras maneiras de pensar a língua inglesa coletivamente com alunos e comunidade não acadêmica dentro do espaço da Universidade.

Nesse sentido, a educação que oprime, segundo Paulo Freire, é a educação que não oferece aos seus indivíduos a capacidade de "indoutrinar-se" contra a "acomodação ao mundo da opressão" (FREIRE, 2005, p. 76). Em igual sentido, a leitura do cânone, embora necessária, prazerosa e significativa, exclui parte dos alunos e não leitores, que não se encontram motivados a contemplar a realidade ficcional-literária oferecida pelas obras clássicas, seja por questões de autoestima, seja por quaisquer outros motivos que impeçam esse aluno de acessar essa literatura, como já apontados anteriormente. 
Para Compagnon "a literatura é o próprio entrelugar, a interface" mas é ainda cercada por "violenta lógica binária, terrorista, maniqueísta, tão ao gosto dos literatos" (2014, p. 135). É contra a condução de práticas docentes excludentes, que privam os alunos de práticas que libertam e que propiciam prazer e liberdade acadêmica que o projeto de leitura de YA de que trata o presente estudo, se consubstancia, enveredando na possibilidade de oferecer aos alunos leitura leve, atual, objetiva, em consonância com o objetivo de aprender e praticar a língua inglesa e ao mesmo tempo de poder questionar e debater sobre os discursos excludentes e elitistas que cerceiam a leitura de clássicos e não clássicos. Segundo Michèle Petit (2013), para formar leitores é preciso desconstruir os medos que, geralmente, cerceiam esses leitores, sejam as inseguranças pessoais de cada leitor ou o desestímulo que muitos leitores recebem de pessoas não leitoras em seu entorno, ao longo da vida. Para Petit (2013, p. 34) "Conhecê-los bem [os medos]" nos permitirá ajudar as pessoas que desejam se aproximar dos livros a transgredir as proibições".

A importância de aproximar potenciais leitores de temáticas que efetivamente possam dialogar com os anseios desses jovens e de uma língua estrangeira hegemônica em uma região de fronteira - local onde ocorrem os encontros do clube de leitura, conforme será explicado mais adiante - é de crucial relevância para pensar quais modelos de atividades, quais dinâmicas e recursos podem ser empregados em projetos que visem incentivar a prática de leitura em língua inglesa para o público jovem adulto, para o aluno do ensino superior público, e principalmente para a comunidade não-acadêmica, em um contexto em que os saberes sofrem um processo cada vez mais notório de hierarquização e estruturação desse conhecimento, de forma a conferir status ao que é conhecimento de prestígio e o que é conhecimento da margem. Embora muitos pensadores contemporâneos criticam essa fronteira do conhecimento de prestígio e do não-prestígio muito ainda pode ser discutido em termos de inclusão e acesso através de um projeto de leitura YA para jovens universitários e comunidade não acadêmica, principalmente sob a ótica decolonial, que questiona exatamente a lógica binária e violência, de que nos fala Compagnon.

${ }^{1}$ Grifo meu 
Nesse sentido, o projeto de extensão de leitura de YA tem como alguns de seus objetivos promover a democratização do acesso à leitura em língua inglesa entre comunidade acadêmica e não acadêmica; promover a discussão de temas importantes para a formação do indivíduo; incentivar o debate, a interação e a socialização do conhecimento; incentivar o prazer da experiência de leitura em outro idioma, consequentemente documentando a experiência individual e o progresso de leitura na língua inglesa e ainda comparar o progresso inicial e o progresso final de desempenho nas leituras do grupo; pensar a língua inglesa e seu prestígio sob a ótica decolonial; refletir sobre as hierarquias do conhecimento imposta no contexto acadêmico.

\section{PERCURSO METODOLÓGICO}

O projeto de extensão "Clube de Leitura de YA" vinculado à Diretoria de Extensão da Universidade Federal de Roraima teve chamada pública para que alunos, servidores e a comunidade roraimense pudessem inscrever-se no projeto.

\subsection{A biografia do leitor: os participantes do Clube de Leitura de YA e a estrutura dos encontros}

O projeto de extensão, que se encontra em vigor desde março de 2018 , buscou selecionar participantes da Universidade (alunos e servidores) e comunidade não acadêmica. Esse objetivo mostrou-se bem-sucedido a princípio, uma vez que os indivíduos inscritos no projeto, não conseguiram mais participar do projeto alegando falta de tempo. É curioso observar que a falta de tempo figura como barreira principal ao hábito da leitura. Na pesquisa Retratos da Leitura no Brasil (2016), 43\% dos entrevistados alegaram não terem lido mais por falta de tempo. Em resposta ao questionário estruturado respondido pelos participantes do grupo de Leitores Iniciantes do Clube de Leitura de YA (entrada em 2019.1), cerca de 65\% também alegaram falta de tempo, associado a cansaço e muito tempo perdido em redes sociais.

Atualmente o projeto de extensão é dividido em dois grupos: (i) Leitores Avançados, que entraram em 2018.1 e (ii) Leitores Iniciantes, que entraram em 
2019.1. A divisão entre grupo Iniciante e Avançado de leitores não necessariamente reflete o nível de inglês do participante, pois a pesquisadora entende que cada leitor é um mundo em si mesmo, com seu ritmo de leitura e com sua dinâmica e, portanto, não cabe à pesquisadora julgar e hierarquizar esses saberes individuais. Entretanto, com o intuito de didatizar e sistematizar a informação frente ao Diretório de Extensão da Universidade, deu-se preferência para usar esse formato de divisão: avançados são os participantes do grupo de 2018 e iniciantes refere-se aos que acabaram de ingressar no projeto. $O$ grupo dos Leitores Avançados é formado em sua maioria por alunos da Universidade oriundos dos cursos de Letras, Matemática, Relações Internacionais, Antropologia, Geologia e História. O grupo dos Leitores Iniciantes é dividido entre não acadêmicos da Universidade, que ficaram sabendo da iniciativa através de reportagem da TV local, ou seja, indivíduos da comunidade boavistense, e alunos da Universidade dos cursos de Psicologia, Relações Internacionais, Jornalismo, Direito, entre outros. O grupo dos Leitores Iniciantes conta ainda com a participação de servidores do quadro de funcionários da Universidade.

Os encontros são mensais, separados entre os grupos de Leitores Iniciantes e Avançados, possuem duração de cerca de 2 horas e pode ser divido nos seguintes momentos: (i) fala individual, em que cada participante dá uma nota ao livro, argumenta os motivos que os levaram a dar aquela nota, fala sobre a experiência com o idioma e o conteúdo do livro; (ii) fala coletiva, em que todos manifestam interesse em explorar a temática do livro, dissecando personagens favoritos ou não, problemas de enredo e estilo de escrita do autor, discussão de termos literários empregados na obra, (iii) explanação sobre conteúdos relacionados à língua inglesa e às hierarquias de conhecimento. As discussões não são ministradas em inglês, pois o intuito é que os participantes avancem no desenvolvimento e aquisição de vocabulário e prática de leitura. $O$ foco primordial do clube de leitura será sempre o de incentivar a leitura em inglês, para que os alunos criem autonomia e interesse em ler na língua estrangeira e escolham em um momento futuro, quando estiverem mais confortáveis, ler outros gêneros em língua inglesa, dentre eles os clássicos.

Os livros escolhidos obedecem a uma ordem de dificuldade que vai do nível mais elementar ao nível mais avançado da língua, respeitando o nível de familiaridade e contato com o idioma dos participantes, por isso, uma rápida verificação da familiaridade dos alunos com o idioma fora feito no início do projeto. 
Os participantes do Clube de Leitura de YA foram submetidos a entrevistas de tipo estruturada e semiestruturada para melhor compreensão de seus processos e perfis. A cada encontro, o leitor participante preenche uma ficha, um travel log ou uma espécie de diário de bordo sobre suas experiências de leitura com as estruturas linguísticas que mais chamaram atenção.

Como os encontros acontecem sempre 1 vez por mês, cada participante tem o compromisso de responder um total de 12 fichas ao término do ano. É importante frisar que as fichas nem sempre foram preenchidas, pois à medida que os participantes se sentiam mais seguros com a língua e com seus próprios ritmos de leitura, não existia mais a necessidade de registrar a experiência de leitura do livro do mês; apenas experienciar o momento de leitura e objetivar cada vez mais leituras mais complexas.

É comum os leitores participantes do projeto extensionista relatarem que foram introduzidos ao hábito de leitura por intermédio de educadores, professores, bibliotecários ou parentes próximos. A figura do mediador, nesse sentido, é importante para familiarizar o não-leitor com o texto escrito. Beaud (apud PETIT, 2009 , p. 10) acredita que "a relação com a cultura escrita é um elemento essencial para o êxito escolar, é mesmo a chave de tudo". E para Petit (2013), a figura feminina é a responsável por introduzir potencial leitores ao hábito da leitura, seja na figura da mãe, da irmã ou de uma profissional das Letras ou da Biblioteconomia. Esse dado, coincide em grande medida com o perfil dos participantes do projeto de extensão que foram introduzidos ao universo leitor pelas mães, tias, primas ou profissionais mulheres.

Para muitos dos participantes do projeto extensionista, ler livros Young Adult literatura não canônica - é a oportunidade de reconhecer seus próprios preconceitos e superá-los. De acordo com Ginzburg (2008, p. 105) "a posição canônica é alheia a interesses democráticos (...). Trata-se ostensivamente de uma arena política, sem deixar de ser um debate no campo estético". Os livros de YA, na contramão da homogenia de pensamento, de escrita e de saberes, produz personagens negros, personagens trans, mães solteiras, órfãos, adolescentes depressivos, personagens com síndromes raras, dentre outros personagens excluídos e menos favorecidos da estrutura social. Longe de querer advogar aqui em favor do que deve ser legitimado institucionalmente como leitura obrigatória ou não em escolas e universidades, o 
objetivo desse projeto extensionista é apontar na direção de outros saberes, e quiçá reparar desigualdades estruturais de acesso a esse idioma de prestígio. Seguindo essa lógica, "livros associados à tentativa de resgate de vozes silenciadas pela história podem encontrar dificuldades de circulação e recepção. A ilusão de universalidade é mais fácil de construir do que a empatia com a dor do outro" (GINZBURG, 2008, p. 107); e é nessa direção que caminha a proposta extensionista apresentada aqui.

\subsection{O projeto de extensão e a interação com a comunidade não-acadêmica}

A Extensão universitária como política de diálogo e intercâmbio com a comunidade não-acadêmica surgiu na Inglaterra em meados do século XIX e no Brasil a partir dos anos 60 do século XX, em meio ao período militar. A Constituição Federal de 1988, no art. 207, atrela ensino, pesquisa e extensão no meio universitário, assim como a Lei de Diretrizes e Base de 1996 estabelece o mecanismo da extensão como uma das finalidades da Universidade brasileira. Cada vez mais as extensões acadêmicas voltam-se para uma vertente mais comunicadora e menos assistencialista; o sentido de transmissão unilateral e hierarquizada do conhecimento dá espaço para um lugar de compreensão, troca de saberes, debate e socialização horizontal e colaborativa envolvendo alunos, professores e participantes de uma forma geral (GADOTTI, 2017).

Para Gadotti:

\footnotetext{
Muitos veem na Extensão Universitária uma forma de responder à atual crise da universidade. É como se a Extensão Universitária pudesse iniciar um processo de transformação da universidade como um todo. A universidade que temos está muito centrada no ensino e na pesquisa e, por meio de um novo paradigma da Extensão Universitária, a própria universidade pudesse ganhar um novo sentido (GADOTTI, 2017, p. 3)
}

No ano em que este trabalho está sendo desenvolvido, um corte de cerca de $30 \%$ foi anunciado para a pasta da Educação e que atingiu, especialmente, o fomento direcionado para atividades de extensão das Universidades Federais brasileiras, local onde esse projeto ocorre. Movimentos de defesa pela emancipação da educação e garantia da democracia eclodem por todo o país e reafirmam a importância cada vez mais premente de pensar os mecanismos que envolvem o 
projeto político-pedagógico da universidade, entre eles os projetos de extensão. É importante pensar qual tipo de extensão fortalece o propósito da universidade e qual tipo favorece o que Boaventura de Sousa Santos chama de "comercialização do conhecimento científico" (2011, p. 40) baseado em uma lógica neoliberal de produção economicista capitalista que se enraíza nas estruturas da educação pública, moldando-as no curto e longo prazos.

A prática extensionista que se volta para os anseios mercadológicos e que se desassocia do ensino e da pesquisa tende a aprofundar a crise pela qual passa as universidades hoje - seja nos países periféricos ou centrais. Essa prática precisa olhar para dentro da universidade e precisa refletir sobre as demandas reivindicadas pela comunidade não acadêmica, como forma de responsabilizar-se socialmente pela troca de conhecimento entre acadêmicos e população geral, a fim de evitar incorrer em um processo de produção de conhecimento descontextualizado e ditado pelos pesquisadores dos centros de pesquisa das universidades. A lógica de produção e aplicação de conhecimento entre pesquisador e aqueles não pertencentes à academia não pode ser verticalizada e irrefletida, uma vez que imprime uma troca "segundo hierarquias organizacionais bem definidas" (SANTOS, 2011, p. 40), o que não condiz com a estrutura extensionista que se almeja.

A prática extensionista hoje, em um contexto de cortes orçamentários, perseguição político-ideológica e anti-intelectualismo, precisa ir além das necessidades que atendem um projeto de poder excludente e hegemônico, mas sobretudo, precisa engajar, democratizar, abrir portas e conferir acesso àqueles que não podem fazer parte do ethos universitário. É por isso que o projeto de extensão a que se refere o presente artigo, buscar ir além do comprometimento com o ensino da língua inglesa a partir da leitura de livros do gênero YA, mas procura também ampliar o tempo de leitura desses participantes, aumentar o repertório deles, incentivar o prazer pela experiência de leitura, formar futuros mediadores de leitura e formadores de opinião críticos e conscientes do conhecimento binário e hierarquizado e questionadores desse modelo.

O projeto de extensão busca além dos objetivos mencionados pensar a língua inglesa como língua franca frente a diversas situações sociolinguísticas, que os empoderem, em uma região de fronteira no Norte do Brasil, mas que sobretudo, torne-os cônscios das diversas formas de uso da língua, além da variedade 
monolíngue do falante nativo. Pensar sobre o tipo de inglês, as assimetrias que enfrentam os diversos falantes na região de fronteira e as situações comunicativas em inglês que os participantes do projeto de extensão encontram na fronteira e no mundo, em que os limites do homogêneo e do heterogêneo, do local e do global convivem no mesmo espaço é a força do projeto em questão.

\subsection{Clube de Leitura de YA e o aprendizado de língua inglesa na região de tríplice fronteira}

Roraima localiza-se no extremo norte do país. É o estado mais setentrional da Federação e que deixou de ser Território Federal com a CF de 1988. Faz fronteira com a Venezuela, ao norte e ao noroeste e com a Guiana (Inglesa) ao leste. Sua capital, Boa Vista, tem cerca de 380 mil habitantes de acordo com o último censo do IBGE. Sua paisagem linguística e cultural é composta por uma variedade de grupos étnicos indígenas (Macuxi, Waiwai, Yanomami, Taurepang, etc) e por residentes guianenses, oriundos da capital da Guiana, Georgetown, ou de cidades menores, como a cidade vizinha, Lethem; e por residentes e refugiados venezuelanos provenientes de Caracas, Pacaraima, Porto Ordaz, entre outras cidades.

Nesse contexto, a Universidade Federal de Roraima, conta com alunos das nacionalidades citadas acima - venezuelanos e guianenses, além daqueles oriundos de territórios indígenas do Estado de Roraima. É dentro desse contexto vibrante e multicultural que o projeto de extensão literário de livros de YA ambienta-se. Partindo de um espaço heterogêneo, como o Estado de Roraima (mais precisamente a cidade de Boa Vista) o projeto de extensão em foco busca contemplar o ensino de uma língua hegemônica e de poder, como a língua inglesa, em um local que já se constitui multilíngue em sua base, em suas origens e ainda refletir sobre o conhecimento canônico e não canônico através de uma perspectiva decolonial.

Como aponta Canagarajah (2009, p. 12, tradução minha) "existem diversas práticas, discursos e tendências ideológicas que constituem o conhecimento local", 2 o que não impede esse conhecimento de ser reconstruído e repensado através de uma negociação de valores e contra valores, uma vez que "celebrar o conhecimento

\footnotetext{
2 "There are diverse practices, discourses, and ideological tendencies that constitute local knowledge".
} 
local, dessa forma, não significa prender-se a uma forma mítica do conhecimento local, como a posse de respostas para todas as perguntas contemporâneas (...)" (ibid., p. 12, tradução minha). ${ }^{3}$ Isso revela que é possível pensar o local sem esquecer que ele se encontra inserido no global e é influenciado por ele; ou seja, as ferramentas usadas na construção e análise do conhecimento local perpassam pelos instrumentos hegemônicos do saber global. Não para diminuir o conhecimento local, mas para "quebrar os moldes hermenêuticos disponíveis e empoderar o conhecimento local" (ibid., p. 12, tradução minha). ${ }^{4}$

Para Canagarajah (2009) o conhecimento local é um processo que negocia práticas e discursos e que se envolve na construção de um novo conhecimento que seja relevante para a sociedade e que leve em consideração o contexto em que esse saber é construído. O contexto em que estamos inseridos é fundamental para dar a base do conhecimento que estamos produzindo. Nesse sentido, uma prática extensionista que se propõe a ler livros não clássicos e consagrados, mas simplesmente livros de uma literatura marginalizada e acessível, abre portas e amplia o horizonte de conhecimento dos participantes por meio de um conhecimento não hegemônico, em uma área de fronteira tríplice periférica, cercada por uma população amazônida, ribeirinha, indígena, estrangeira de pouco prestígio, como refugiados e nacionais de países como a Venezuela - país no epicentro da questão migratória - e a Guiana.

Para Canagarajah (ibid., p. 17, tradução minha): "Em comunidades ocidentais relativamente mais homogêneas, onde nações têm sido tradicionalmente definidas com base em grupos de linguagem, a noção de identificação de língua unitária faz total sentido". Não é o caso dos participantes do projeto extensionista em questão, uma vez que os leitores do clube de leitura são influenciados em grande medida pelo entorno regional da região amazônica fronteiriça e pela necessidade premente de comunicarem-se em língua inglesa (e também espanhola) à medida que a imposição linguística é uma necessidade real na região.

A importância desse projeto consiste em manter um diálogo aberto com alunos

\footnotetext{
3 "Celebrating local knowledge, therefore, does not mean holding up a mythical form of classical knowledge as possessing the answers to all contemporary questions".

4 "(...) to break the available hermeneutic molds to empower local knowledge".

5 "In relatively more homogeneous Western communities, where nations have traditionally been defined on the basis of language groups, the notion of unitary language identification makes good sense".
} 
e comunidade interessada em participar de um clube de leitura de língua inglesa, com o compromisso de aprender o idioma e desenvolver a habilidade de leitura, reforçando-a como hábito e direito cidadão, possibilitando ao participante do projeto que perceba ao seu próprio tempo, seu percurso como leitores de língua inglesa. Os participantes não abandonam seus saberes locais quando participam de um clube de leitura de língua inglesa com livros de literatura jovem adulto. Pelo contrário, suas identidades multicarregadas de conhecimentos híbridos, não se sobrepõem, nem se submetem ao conhecimento global. É assim, que nesse processo "o leitor muda e renova suas leituras ao sabor de suas experiências; abandona ou retoma a prática de leitura, modifica suas escolhas (...). O amor pela leitura se descobre ou se redescobre em diversos períodos da existência" (LAFARGE; SEGRÉ, 2010, p. 123124). Pensar a imposição da língua inglesa como conhecimento indispensável em uma região de fronteira e como saber primordial para inserção no mercado de trabalho e projeção acadêmica sob a lógica decolonial, promove o despertar rumo ao entendimento dos processos ligados à colonização promovidos e reforçados pelo ensino da língua inglesa, que está no centro da promoção desses processos.

\section{PERCURSO TEÓRICO À GUISA DO PENSAMENTO DECOLONIAL}

A discussão que se pretende alavancar nesse espaço será elaborada com base no pensamento Decolonial Latino-americano. A proposta decolonial tem o intuito de pensar a produção intelectual e toda a construção do conhecimento a partir das margens, das fronteiras, dos limites dos excluídos, usando práticas e lógicas que foram historicamente apagadas ou negligenciadas por uma matriz de dominação colonial que se estrutura há séculos.

Discute-se aqui de que forma uma formação intercultural e crítica propiciada através de uma proposta de ensino e reflexão sobre a língua inglesa em um projeto extensionista voltada para o público de uma Universidade Pública no extremo norte do país e sua respectiva comunidade pode contribuir para questionar e substituir um modelo tradicional e elitista por um novo modelo de educação superior com base na necessidade de implementar um pensamento decolonial na Universidade pública gratuita e de qualidade e expurgar de suas estruturas, modelos calcados a partir de formatos eurocêntricos de pensamento único. 
Dessa forma, pensar o ensino, a discussão e a reflexão sobre a língua inglesa a partir de livros não clássicos dá aos participantes do projeto a possibilidade de lerem no idioma, fazerem sentido desse idioma e empoderarem-se desse idioma para os mais diversos usos com o intuito de liberarem-se da colonialidade do pensamento, o lado obscuro da modernidade, nas palavras de Mignolo (2000). Os clássicos possuem espaço privilegiado na construção do conhecimento nas Universidades, ao contrário do que acontece com a literatura Young Adult, frequentemente marginalizado nos espaços voltados à troca e à construção de conhecimento. Os próprios participantes do projeto relutam de início em participar de uma roda de discussão e leitura que terá como base a leitura de livros de YA, privando-os a si próprios de uma reflexão acerca da literatura de massa que pode propiciar discussões tão aprofundadas, engajadas e significativas quanto a leitura de clássicos, ao mesmo tempo que favorece o aprendizado da língua inglesa, foco da maioria daqueles que procuram o projeto. É importante frisar que ler YA também pode ser uma prática que conduza a um pensamento decolonizado e que construa o conhecimento com base em uma pedagogia decolonial crítica.

O conhecimento produzido e aceito nas Universidades do mundo ocidental é regido por uma ótica binária de racionalidade cartesiana. O mito do Ego geraria uma falsa noção de objetividade e neutralidade, fruto de um diálogo imparcial e monológico com o eu. Todo conhecimento que foge dessa lógica do egopolítico cartesiano é tido como irrelevante e inferior. Para Grosfoguel (2016, p. 46) as "universidades têm operado a partir de um uni-versalismo no qual 'um (homem ocidental de cinco países) define pelos outros' o que é conhecimento válido e verdadeiro"

Nesse sentido, para fazer a dissociação dessa estrutura arraigada de produção, concepção, absorção e legitimação do conhecimento, é preciso descolonizar as bases desse conhecimento, de forma a reconhecer o racismo, o sexismo e o preconceito epistêmico que faz parte da estrutura das universidades ocidentais e que estão em voga desde antes do bem-sucedido projeto de avanço colonial das potências europeias em direção ao novo mundo; reconhecimento da diversidade epistêmica que daria voz a uma pluralidade de tradições e conceitos não cristãos, ocidentais, patriarcais, colonialistas, e finalmente o rompimento com 0 universalismo homogêneo e o saber único tal qual se configura hoje 
(GROSFOGUEL, 2016).

O projeto de extensão em questão propõe a leitura de livros não clássicos, não pertencentes ao cânone, com o intuito de expandir as leituras desses participantes e contemplar temas que promovam a diversidade, o respeito e a inclusão, e que podem ser considerados como inacessíveis de alguma forma via literatura tradicional por diversas razões - desde a barreira com a língua até a dificuldade de acesso a livros tidos como mais elitizados, simplesmente por pertencerem a editoras e segmentos literários que muitos leitores (e principalmente não leitores) presumem ser impossível de compreender ou de gostar. Muitos participantes do Clube de Leitura reportam o desinteresse por obras que eles/elas acreditam ser inacessíveis, mesmo que exista a tradução para a língua vernácula. Além disso, o conhecimento uniforme e uni-versal a que Grosfoguel (2016) se refere é claramente percebido nas hierarquias simbólicas pré-estabelecidas pelos próprios leitores/participantes do projeto, que entendem a língua inglesa como uniforme e pertencente a uma cultura de países ocidentais capitalistas, brancos e ricos, e portanto, pertencentes à Europa ou à América do Norte. Como residentes na cidade de Boa Vista, vizinha à Guiana, país de língua inglesa, espera-se que os participantes englobem o país vizinho entre os países falantes de língua inglesa de sua preferência, o que não ocorre, devido às hierarquias do conhecimento que diminuem a produção literária do país vizinho anglofônico.

Ao considerarem o inglês como língua de prestígio e ascensão social não é sequer cogitada a produção de livros na Guiana, país falante de língua inglesa, o que se configura como um contrassenso, visto a proximidade entre os dois países e a contínua influência e intercâmbio entre ambos - seja devido ao fluxo de pessoas, comércio ou mesmo cooperação técnica entre os dois países. A própria noção de que o inglês padrão e relevante seja o inglês britânico (alimentado também por guianenses residentes em Boa Vista-RR) vem aos poucos sendo substituído pela hegemonia linguística e espacial, associado ao inglês dos Estados Unidos, como país tido por muitos participantes do projeto extensionista como avançado, moderno e com mercado editorial aquecido na produção de YA. Na visão do participante isso significa mais possibilidade de aprender a língua inglesa, uma vez que os EUA apresentam vasta publicação editorial de livros do gênero YA ou de livros de uma forma geral, e logo, maior contato com materiais autênticos. Para Mignolo: 
O inglês americano está se tornando cada vez mais a língua das transações internacionais e paradoxalmente está desafiando a unidade linguística da comunidade europeia, onde o inglês americano ofusca o legado Inglês, como a língua do Império Britânico. Não é apenas a gramática da língua que está em jogo, mas a sua geopolítica (MIGNOLO, 2000, p. 255) ${ }^{6}$

Pensar o projeto extensionista dentro de um âmbito de discussões que também pensa acerca de língua de poder, ensino-aprendizado de língua e decolonialidade combate pensamentos e práticas excludentes e elitistas que apesar do término das antigas formas colonizadoras, a colonialidade ainda sobrevive e persiste.

\section{CONCLUSÃO}

Em seu segundo ano de realização, o Clube de Leitura de YA conseguiu formar um grupo sólido de leitores de língua inglesa que alcançaram bom desempenho ao longo do projeto e tiveram avanços consideráveis em velocidade de leitura, compreensão do idioma e acúmulo de novo vocabulário. Esses (novos) leitores de língua inglesa estão motivados a dar continuidade ao Clube. Sendo assim, o Clube de Leitura só tende a expandir.

Espera-se que os alunos se envolvam com a prática de leitura em língua estrangeira e consigam avançar no aprendizado de vocabulário e estruturas linguísticas mais complexas do idioma. A expectativa é que os alunos compartilhem seus processos de leitura e aprendizado com os outros colegas formando uma corrente de incentivo coletivo à leitura de ficção em língua estrangeira, consequentemente mantendo todos motivados. Ademais, o clube de leitura favorece o entrosamento e a interação extraclasse. O retorno para a comunidade acadêmica e não acadêmica é de grande valia para todos e todas envolvidos/as na prática, uma vez que os ganhos são praticamente imediatos e se refletem na escrita acadêmica e atividades de oralidade desempenhados pelos alunos em sala de aula, assim como ajuda a formar indivíduos mais conscientes sobre o que é língua, quais os mecanismos de poder em torno das línguas, de que forma um agir e pensar decolonial promove a igualdade entre falantes não nativos.

\footnotetext{
${ }^{6}$ Do original: "American English is becoming more and more the language of international transactions and, paradoxically, is challenging the linguistic unit of the European community, where American English overshadows English's legacy as the language of the British Empire. It is not just the grammar of the language that is at stake, but the geopolitics of language" (tradução minha).
} 
À medida que os participantes vão familiarizando-se com a dinâmica do Clube de Leitura e com as discussões sutis e não sutis acerca da temática YA como forma de combate a discursos discriminatórios e excludentes e do aprendizado da língua através de leitura prazerosa e acessiva que rodeiam os encontros, os participantes começam a empoderar-se como leitores e compreenderem a leitura como um direito cidadão de todos.

\section{REFERÊNCIAS}

CANAGARAJAH, S. Reclaiming the local in language policy and practice. Mahwah; London: Routledge, 2009.

COMPAGNON, A. O Demônio da Teoria. Belo Horizonte: Editora UFMG, 2014.

FREIRE, P. Pedagogia do Oprimido. Rio de Janeiro: Paz e Terra, 2005.

GADOTTI, M. Extensão Universitária: Para quê? In: INSTITUTO PAULO FREIRE. [S. I.], p. 1-18, 15 fev. 2017. Disponível em: https://www.paulofreire.org/images/pdfs/ Extens\%C3\%A3o_Universit\%C3\%A1ria_-_Moacir_Gadotti_fevereiro_2017.pdf. Acesso em: 2 jul. 2019.

GINZBURG, J. O valor estético: entre universalidade e exclusão. Alea, Rio de Janeiro, v. 10, n.1, p. 98-107, 2008. Disponível em: http://www.scielo.br/pdf/alea/ v10n1/v10n1a07.pdf. Acesso em: 2 jul. 2019.

GROSFOGUEL, R. A estrutura do conhecimento nas universidades ocidentalizadas: racismo/sexismo epistêmico e os quatro genocídios/epistemicídios do longo século XVI. Revista Sociedade e Estado, Brasília, v. 31, n. 1, p. 25-49, 2016. Disponível em: http://www.scielo.br/scielo.php?pid=S010269922016000100025\&script=sci_art text. Acesso em: 2 de jul. 2019.

INSTITUTO PRÓ-LIVRO. Retratos da Leitura no Brasil. São Paulo: Instituto PróLivro, 2016.

LAFARGE, C.; SEGRÉ, M. Sociologia da leitura. Cotia: Ateliê Editoria, 2010.

MIGNOLO, W. Local Histories/Global Designs - coloniality, subaltern knowledges, and border thinking. USA: Princeton University Press, 2000.

MIGNOLO, W.; WALSH, C. On Decoloniality. Concepts, Analytics, Praxis.

Durham; London: Duke University Press, 2018.

PETIT, M. Leituras: do espaço íntimo ao espaço público. São Paulo: Editora 34, 2013. 
PETIT, M. Os jovens e a leitura: uma nova perspectiva. São Paulo: Editora 34, 2009.

SANTOS, B. A Gramática do Tempo: para uma nova leitura política. São Paulo: Cortez, 2010.

SANTOS, B. A Universidade no século XXI: para uma reforma democrática e emancipatória da universidade. São Paulo: Cortez, 2011.

\section{Sobre a autora}

\section{Martha Julia Martins de Souza}

Professora do curso de Letras Português-Inglês e do Programa de Mestrado em Letras na Universidade Federal de Roraima. Doutora e mestra em Estudos Linguísticos e Literários pelo Programa de Pós-Graduação em Inglês da Universidade Federal de Santa Catarina e licenciada em Letras (Português-Inglês) pela Universidade Estadual do Maranhão. Tem como interesses de pesquisa os estudos de gênero e as epistemologias anti-hegemônicas. É coordenadora do grupo de pesquisa de Estudos de Gênero (GREG) e coordena um projeto de extensão de incentivo à leitura em língua inglesa. 